\title{
Correlation between plasma osteopontin levels and aortic valve calcification: Potential insights into the pathogenesis of aortic valve calcification and stenosis
}

\author{
Pey-Jen Yu, MD, ${ }^{\mathrm{a}}$ Adam Skolnick, MD, ${ }^{\mathrm{b}}$ Giovanni Ferrari, PhD, ${ }^{\mathrm{a}}$ Katherine Heretis, MD, ${ }^{\mathrm{a}}$

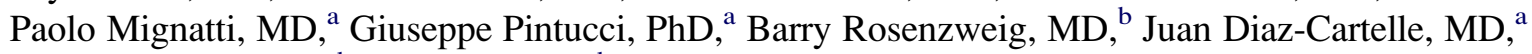 \\ Itzhak Kronzon, MD, ${ }^{\mathrm{b}}$ Gila Perk, MD, ${ }^{\mathrm{b}}$ Harvey I. Pass, MD, ${ }^{\mathrm{a}}$ Aubrey C. Galloway, MD, ${ }^{\mathrm{a}}$ \\ Eugene A. Grossi, MD, ${ }^{\mathrm{a}}$ and Juan B. Grau, MD ${ }^{\mathrm{a}}$
}

\begin{abstract}
Objective: The inflammatory process of aortic stenosis involves the differentiation of aortic valve myofibroblasts into osteoblasts. Osteopontin, a proinflammatory glycoprotein, both stimulates differentiation of myofibroblasts and regulates the deposition of calcium by osteoblasts. Osteopontin levels are increased in patients with such conditions as end-stage renal disease, ectopic calcification, and autoimmune disease. We hypothesized that increased plasma osteopontin levels might be associated with the presence of aortic valve calcification and stenosis.
\end{abstract}

\begin{abstract}
Methods: Venous blood from volunteers older than 65 years undergoing routine echocardiographic analysis or aortic valve surgery for aortic stenosis was collected. Plasma osteopontin levels were measured by means of enzyme-linked immunosorbent assay. The presence of aortic stenosis was defined as an aortic valve area of less than $2.0 \mathrm{~cm}^{2}$. Aortic valve calcification was assessed by using a validated echocardiographic grading system (1, none; 2, mild; 3, moderate; 4 , severe). Comparisons were performed with nonpaired $t$ tests.
\end{abstract}

Results: Aortic stenosis was present in 23 patients (mean age, 78 years) and was absent in 7 patients (mean age, 72 years). Aortic valve calcification scores were $3.5 \pm 0.6$ and $1.3 \pm 0.5$ in patients with and without aortic stenosis, respectively $(P<.001)$. Patients with no or mild aortic valve calcification had lower osteopontin levels compared with patients with moderate or severe aortic valve calcification $(406.1 \pm 165.8$ vs $629.5 \pm 227.5$ $\mathrm{ng} / \mathrm{mL}, P=.01)$. Similarly, patients with aortic stenosis had higher osteopontin levels compared with patients without aortic stenosis $(652.2 \pm 218.7$ vs $379.7 \pm 159.9 \mathrm{ng} / \mathrm{mL}, P<.01)$.

Conclusion: Increased levels of plasma osteopontin are associated with the presence of aortic valve calcification and stenosis. These findings suggest that osteopontin might play a functional role in the pathogenesis of calcific aortic stenosis.

Aortic valve calcification is a prevalent condition that is found in $21 \%$ to $26 \%$ of adults older than 65 years. ${ }^{1,2}$ In addition to being independently associated with an increased risk of death from cardiovascular causes, the degree of aortic valve calcification has also been correlated with the presence and progression of calcific aortic stenosis. ${ }^{3,4}$ With a prevalence of $3 \%$ to $9 \%$, calcific aortic stenosis is also the most prevalent valvular disease and the main cause for valve replacement in patients older than 60 years. Although calcific aortic stenosis is a gradually progressive disease characterized by a long asymptomatic phase, severe symptomatic aortic stenosis is associated with a life expectancy

From the Departments of Cardiothoracic Surgery ${ }^{\mathrm{a}}$ and Medicine, ${ }^{\mathrm{b}}$ Division of Cardiology, New York University Medical Center, New York, NY.

Received for publication June 20, 2008; revisions received Sept 21, 2008; accepted for publication Oct 31, 2008.

Address for reprints: Juan B. Grau, MD, New York University Medical Center, 530 First Ave, Skirball Institute Suite 9V, New York, NY 10016 (E-mail: jbgrau@ yahoo.com).

J Thorac Cardiovasc Surg 2009;138:196-9

$0022-5223 / \$ 36.00$

Copyright (c) 2009 by The American Association for Thoracic Surgery doi: 10.1016/j.jtcvs.2008.10.045 of less than 5 years, ${ }^{5}$ and surgical intervention remains the definitive treatment for aortic stenosis. Despite the high prevalence and mortality associated with both aortic valve calcification and stenosis, little is known about the molecular mechanisms driving their pathogenesis.

The development of calcific aortic valve disease is characterized by 3 primary processes: lipid accumulation, ${ }^{6}$ inflammation, ${ }^{7-9}$ and ultimately calcification. ${ }^{10}$ The finding that the multifunctional glycophosphoprotein osteopontin (OPN) is involved in both cell-mediated inflammation and biomineralization has generated considerable interest in the role of OPN in ectopic calcification and calcific aortic valve disease. In the present study we describe the association between increased plasma OPN levels and the presence of aortic valve calcification and stenosis.

\section{MATERIALS AND METHODS Patient Selection}

Between April 2007 and September 2007, venous blood specimens were collected from patients undergoing routine echocardiographic analysis and from patients undergoing scheduled aortic valve surgery. Institutional review board approval (H\#07-086) and informed consent were obtained. 


\section{Abbreviation and Acronym \\ $\mathrm{OPN}=$ osteopontin}

Clinical information was obtained by means of patient interview and chart review. Patient selection was limited to those older than 65 years. Exclusion criteria included patients with serum creatinine values of $1.5 \mathrm{mg} / \mathrm{dL}$ or greater; bicuspid aortic valve; premature menopause, osteoporosis, or both; prior aortic valve surgery; rheumatic heart disease; endocarditis; active malignancy; chronic liver failure; calcium regulation disorders (hyperparathyroidism, hyperthyroidism, and hypothyroidism); and chronic or acute inflammatory states (sepsis, autoimmune disease, and inflammatory bowel disease).

\section{OPN Measurement}

Ethylenediamine tetra-acetic acid-anticoagulated blood specimens were immediately centrifuged, and the plasma was stored at $-80^{\circ} \mathrm{C}$. Plasma OPN levels were measured in batches by means of enzyme-linked immunosorbent assay with a commercially available kit (Human Osteopontin Assay Kit; Immuno-Biological Laboratories, Minneapolis, Minn), according to the manufacturer's instructions.

\section{Echocardiographic Analysis}

All patients had a comprehensive echocardiographic assessment, including M-mode, 2-dimensional, and color Doppler echocardiographic analysis, conducted by a certified echocardiographer with commercially available ultrasound systems. All measurements were performed according to the American Society of Echocardiography's recommendations. ${ }^{11}$ The presence of aortic stenosis was defined as an aortic valve area of less than 2.0 $\mathrm{cm}^{2}$. Aortic valve calcification was assessed, and a calcium score of 1 to 4 was assigned for each patient by a single cardiologist (GP) based on the method described by Rosenhek and colleagues ${ }^{12}: 1$, no calcification; 2, mildly calcified (small isolated spots); 3 , moderately calcified (multiple larger spots); and 4, severely calcified (extensive thickening and calcification of all cusps).

\section{Statistical Analysis}

Statistical analysis was performed with the statistical software SPSS (Version 15; SPSS, Inc, Chicago, Ill). Continuous variables were analyzed by using the Student's $t$ test and categorical variables by using the $\chi^{2}$ test. Linear and logistic regression analyses were used to determine the correlation between 2 variables.

\section{RESULTS}

Aortic stenosis was present in 23 patients and was absent in 7 patients. Demographic and clinical characteristics of patients with aortic stenosis and control subjects are shown in Table 1. There were no significant differences in the sex, age, comorbidities, blood calcium levels, and calcium-phosphorus product between the 2 groups. Of the patients with aortic stenosis, the average aortic valve area and mean gradient were $0.78 \pm 0.28 \mathrm{~cm}^{2}$ and $37.12 \pm 19.08 \mathrm{~mm} \mathrm{Hg}$, respectively. Patients with aortic stenosis had higher aortic valve calcification scores compared with control subjects $(3.5 \pm 0.6$ vs $1.3 \pm 0.5, P<.001)$.

Plasma OPN levels were increased in patients with moderate-to-severe aortic valve calcification compared with those seen in patients with no or mild aortic valve calcification
TABLE 1. Demographic and clinical characteristics of patients with aortic stenosis and control subjects

\begin{tabular}{lccc}
\hline \multicolumn{1}{c}{ Characteristics } & $\begin{array}{c}\text { Aortic stenosis } \\
(\mathbf{n = 2 3 )}\end{array}$ & $\begin{array}{c}\text { Control subjects } \\
(\mathbf{n}=7)\end{array}$ & $\begin{array}{c}\boldsymbol{P} \\
\text { value }\end{array}$ \\
\hline Age (y) & $78 \pm 7.9$ & $72 \pm 7.1$ & .09 \\
Male sex & $11(47.8 \%)$ & $4(57.1 \%)$ & .66 \\
Smokers & $8(34.8 \%)$ & $1(14.3 \%)$ & .57 \\
Hypertension & $17(78.3 \%)$ & $7(100 \%)$ & .44 \\
Diabetes mellitus & $8(34.8 \%)$ & $3(42.9 \%)$ & 1.00 \\
CVA & $1(4.3 \%)$ & $1(14.3 \%)$ & .95 \\
PVD & $2(8.7 \%)$ & $1(14.3 \%)$ & 1.00 \\
Coronary artery disease & $9(39.1 \%)$ & $1(14.3 \%)$ & .45 \\
Hyperlipidemia & $13(56.5 \%)$ & $5(71.4 \%)$ & .79 \\
AVC score & $3.5 \pm 0.6$ & $1.3 \pm 0.5$ & $<.001$ \\
Adjusted calcium (mg/dL) & $9.2 \pm 0.5$ & $9.3 \pm 0.6$ & .86 \\
CaxP & $32.7 \pm 5.0$ & $31.3 \pm 6.7$ & .69 \\
\hline
\end{tabular}

$C V A$, Cerebral vascular accident; $P V D$, peripheral vascular disease; $A V C$, aortic valve calcification; $\operatorname{Cax} P$, calcium-phosphorus product.

$(629.5 \pm 227.5$ vs $406.1 \pm 165.8 \mathrm{ng} / \mathrm{mL}, P=.01$; Figure 1$)$. Logistic regression of OPN level, age, and adjusted serum calcium level showed only OPN level to be independently associated with degree of aortic valve calcification $(P=.04)$. Plasma OPN levels were also significantly increased in patients with aortic stenosis compared with those in control subjects $(652.2 \pm 218.7$ vs $379.7 \pm 159.9 \mathrm{ng} / \mathrm{mL}, P<.01$; Figure 2). Linear regression analysis showed that plasma OPN levels significantly but weakly correlated with the degree of aortic stenosis $(r=0.41, P=.03)$.

\section{DISCUSSION}

The prevalence of aortic valve calcification increases with age. It is found in $26 \%$ of those older than 65 years and $37 \%$ of those older than 75 years. ${ }^{2}$ Even after adjustment for associated clinical factors, such as age, male sex, smoking, and dyslipidemia, aortic valve calcification is associated with an increased risk of death from cardiovascular causes. ${ }^{13}$ Aortic valve calcification, with or without aortic stenosis, therefore constitutes a significant health problem.

A study conducted by Rosenhek and colleagues ${ }^{12}$ found valvular calcification to be the only independent predictor of outcome in patients with severe aortic stenosis. They

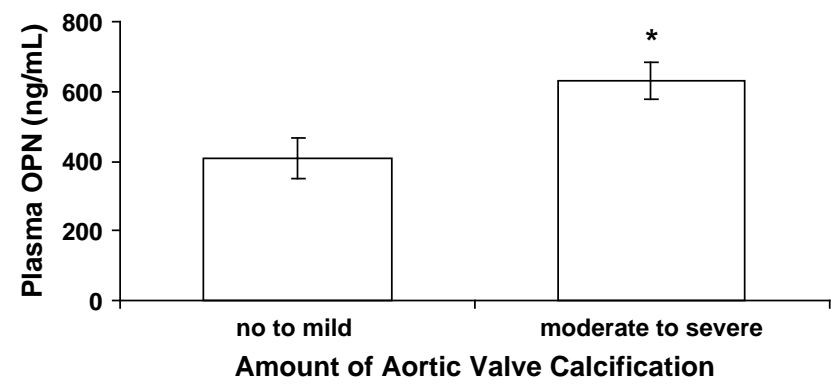

FIGURE 1. Correlation between circulating osteopontin $(O P N)$ levels and aortic valve calcification. Error bars: \pm 1 standard error. $* P=.01$. 


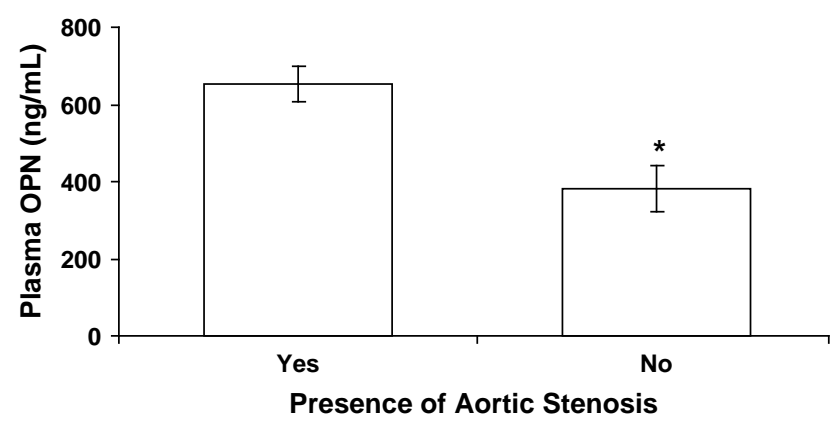

FIGURE 2. Correlation between circulating osteopontin $(O P N)$ levels and aortic stenosis. Error bars: \pm 1 standard error. $* P<.01$.

reported a 1 -year event-free survival of $92 \%$ versus $60 \%$ for patients with no or mild valvular calcification compared with those with moderate or severe calcification. Patients with moderate calcification had similar outcomes to those with severe calcification. By using the same aortic valve calcification scoring and categorization system, our study found increased levels of plasma OPN levels in patients with moderate-to-severe aortic valve calcification compared with those with no to mild calcification. This finding might suggest a future role of plasma OPN levels to risk stratify patients with aortic valve calcification, stenosis, or both for either closer follow-up or earlier surgical intervention.

Both in vitro and in vivo studies have shown that valvular calcification is an active process controlled by inflammatory mediators, the balance between osteoblast-like differentiation and osteoclast recruitment at the tissue level, as well as levels of bone matrix proteins, such as OPN (Figure 3). The hemodynamic severity and progression of aortic stenosis is well correlated with both the presence and degree of aortic valve calcification. ${ }^{3,12,14}$ Increased OPN expression has been found in hypercholesterolemia-induced atherosclerosis and osteoblast-like changes in rabbit aortic valves. ${ }^{15}$ High levels of OPN in native human calcified degenerative aortic valves from patients undergoing valve replacement have been shown by means of immunohistochemistry, reverse transcription-polymerase chain reaction, Western blotting, and in situ hybridization analyses. ${ }^{16-18}$ OPN localizes with macrophages and areas of calcium deposition and varies in proportion to the amount of calcium present. ${ }^{16,17}$ In addition to native valves, increased OPN levels were also found by means of immunohistochemistry in calcified valve allografts. ${ }^{19}$ Similarly, immunostaining and Western blot analysis of explanted glutaraldehyde-pretreated bioprosthetic porcine valves has shown higher OPN levels in calcified compared with noncalcified areas. ${ }^{20}$ It is thus speculated that calcification of the originally acellular bioprosthesis might involve adsorption of proteins, such as OPN from circulating blood.

High levels of circulating OPN have been found in cardiovascular diseases, such as atherosclerosis, ischemic heart

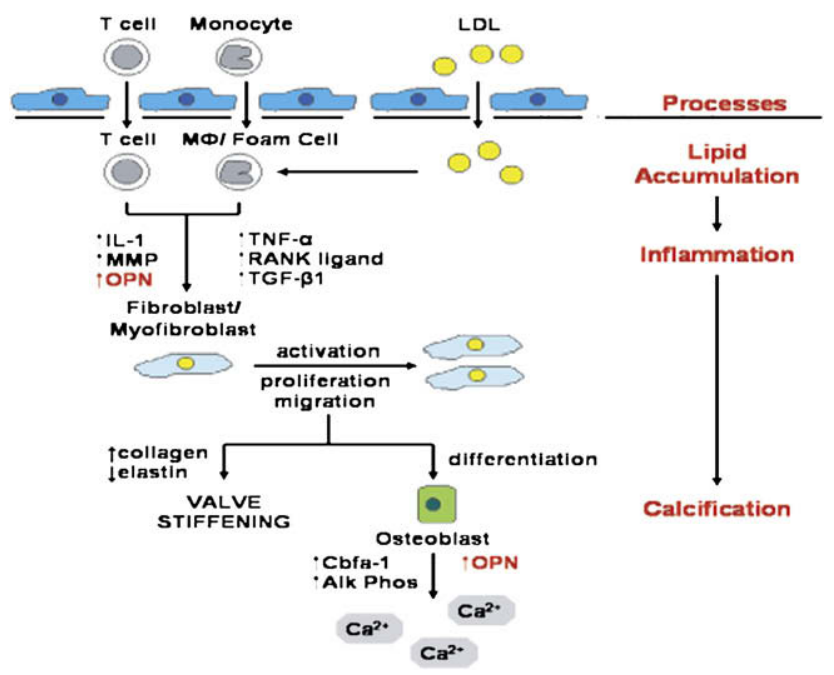

FIGURE 3. Pathogenesis of aortic valve calcification. Active processes involving lipid accumulation, inflammation, and calcification leading to the formation of calcific valvular disease are shown. $I L-1$, Interleukin $1 ; L D L$, low-density lipoprotein; $M \Phi$, macrophage; $M M P$, matrix metalloproteinase; $O P N$, osteopontin; $R A N K$, receptor activator of nuclear factor $\kappa \mathrm{B}$; $T G F$, transforming growth factor; $T N F$, tumor necrosis factor.

disease, heart failure, and rheumatic mitral stenosis. ${ }^{21-24}$ In the present study we describe an association between increased levels of plasma OPN and both aortic valve calcification and the degree of aortic stenosis. Although other serum markers, such as C-reactive protein, ${ }^{25}$ calcium-phosphate product, ${ }^{26}$ and B-type natriuretic peptide ${ }^{27}$ have previously been shown to be associated with aortic calcification and stenosis, OPN is the only molecule that is implicated in both inflammation and biomineralization processes, which lead to aortic valve calcification and subsequent stenosis. Therefore our findings suggest that OPN might play a unique functional role in the pathogenesis of calcific aortic stenosis.

A potential limitation of this study is the semiquantitative nature of the aortic valve calcification scoring system: this variability was minimized by assigning a single blinded cardiologist to the grading of calcium scores. Another limitation is the small study size; although statistically significant, the possibility of type 1 error exists because of other unmeasured cofactors. Importantly, this study was limited to the quantitative assessment of plasma OPN in the presence of aortic valve calcification and stenosis. However, posttranslational modifications of OPN, such as phosphorylation, are key modulators of the biologic function of OPN. Therefore the role of OPN in the development of ectopic calcification might not depend simply on the amount of circulating OPN levels but additionally on the qualitative modification of the molecule. Cell cultures have demonstrated that exogenous OPN inhibits in vitro calcification of smooth muscle cells. ${ }^{28}$ Additionally, in vivo studies with OPN mutant mice further demonstrate that OPN not only inhibits but also promotes active dissolution of ectopic calcification. In 
spite of this, our study and previous studies have found increased levels of OPN in the plasma and valvular tissue of patients with aortic valve calcification and stenosis. These seemingly opposing biologic effects of OPN might be dependent on posttranslational modifications of the molecule. Therefore future studies of the molecular role of OPN in valve calcification might provide new opportunities to modify the progression of aortic valve calcification and stenosis.

\section{References}

1. Lindroos M, Kupari M, Heikkila J, Tilvis R. Prevalence of aortic valve abnormalities in the elderly: an echocardiographic study of a random population sample. J Am Coll Cardiol. 1993;21:1220-5.

2. Stewart BF, Siscovick D, Lind BK, Gardin JM, Gottdiener JS, Smith VE, et al. Clinical factors associated with calcific aortic valve disease. Cardiovascular Health Study. J Am Coll Cardiol. 1997;29:630-4.

3. Davies SW, Gershlick AH, Balcon R. Progression of valvar aortic stenosis: a long-term retrospective study. Eur Heart J. 1991;12:10-4.

4. Nightingale AK, Horowitz JD. Aortic sclerosis: not an innocent murmur but a marker of increased cardiovascular risk. Heart. 2005;91:1389-93.

5. Ross J Jr, Braunwald E. Aortic stenosis. Circulation. 1968;38:61-7.

6. Olsson M, Thyberg J, Nilsson J. Presence of oxidized low density lipoprotein in nonrheumatic stenotic aortic valves. Arterioscler Thromb Vasc Biol. 1999;19:1218-22.

7. Otto CM, Kuusisto J, Reichenbach DD, Gown AM, O'Brien KD. Characterization of the early lesion of "degenerative" valvular aortic stenosis. Histological and immunohistochemical studies. Circulation. 1994;90:844-53.

8. Olsson M, Dalsgaard CJ, Haegerstrand A, Rosenqvist M, Ryden L, Nilsson J. Accumulation of T lymphocytes and expression of interleukin-2 receptors in nonrheumatic stenotic aortic valves. J Am Coll Cardiol. 1994;23:1162-70.

9. Kaden JJ, Dempfle CE, Grobholz R, Tran HT, Kilic R, Sarikoc A, et al. Interleukin-1 beta promotes matrix metalloproteinase expression and cell proliferation in calcific aortic valve stenosis. Atherosclerosis. 2003;170:205-11.

10. Mohler ER 3rd, Gannon F, Reynolds C, Zimmerman R, Keane MG, Kaplan FS. Bone formation and inflammation in cardiac valves. Circulation. 2001;103:1522-8.

11. Gottdiener JS, Bednarz J, Devereux R, Gardin J, Klein A, Manning WJ, et al. American Society of Echocardiography recommendations for use of echocardiography in clinical trials. J Am Soc Echocardiogr. 2004;17:1086-119.

12. Rosenhek R, Binder T, Porenta G, Lang I, Christ G, Schemper M, et al. Predictors of outcome in severe, asymptomatic aortic stenosis. N Engl J Med. 2000;343:611-7.

13. Otto CM, Lind BK, Kitzman DW, Gersh BJ, Siscovick DS. Association of aorticvalve sclerosis with cardiovascular mortality and morbidity in the elderly. $N$ Engl J Med. 1999;341:142-7.
14. Koos R, Kuhl HP, Muhlenbruch G, Wildberger JE, Gunther RW, Mahnken AH Prevalence and clinical importance of aortic valve calcification detected incidentally on CT scans: comparison with echocardiography. Radiology. 2006;241: 76-82.

15. Rajamannan NM, Subramaniam M, Springett M, Sebo TC, Niekrasz M, McConnell JP, et al. Atorvastatin inhibits hypercholesterolemia-induced cellular proliferation and bone matrix production in the rabbit aortic valve. Circulation. 2002;105:2660-5.

16. Mohler ER 3rd, Adam LP, McClelland P, Graham L, Hathaway DR. Detection of osteopontin in calcified human aortic valves. Arterioscler Thromb Vasc Biol. 1997; 17:547-52.

17. O'Brien KD, Kuusisto J, Reichenbach DD, Ferguson M, Giachelli C, Alpers CE, et al. Osteopontin is expressed in human aortic valvular lesions. Circulation. 1995;92:2163-8

18. Rajamannan NM, Subramaniam M, Rickard D, Stock SR, Donovan J, Springett M, et al. Human aortic valve calcification is associated with an osteoblast phenotype. Circulation. 2003;107:2181-4.

19. Shetty R, Pepin A, Charest A, Perron J, Doyle D, Viosine P, et al. Expression of bone-regulatory proteins in human valve allografts. Heart. 2006;92:1303-8.

20. Shen M, Marie P, Farge D, Carpentier S, De Pollack C, Hott M, et al. Osteopontin is associated with bioprosthetic heart valve calcification in humans. $C R \mathrm{Acad} S \mathrm{Sc}$ III. 1997;320:49-57.

21. Minoretti P, Falcone C, Calcagnino M, Emanuele E, Buzzi MP, Coen E, et al Prognostic significance of plasma osteopontin levels in patients with chronic stable angina. Eur Heart J. 2006;27:802-7.

22. Soejima H, Irie A, Fukunaga T, Oe Y, Kojima S, Kaikita K, et al. Osteopontin expression of circulating $\mathrm{T}$ cells and plasma osteopontin levels are increased in relation to severity of heart failure. Circ J. 2007;71:1879-84.

23. Atalar E, Ozturk E, Ozer N, Haznedaroglu IC, Kepez A, Coskun S, et al. Plasma soluble osteopontin concentrations are increased in patients with rheumatic mitra stenosis and associated with the severity of mitral valve calcium. Am J Cardiol. 2006;98:817-20.

24. Soejima H, Irie A, Fukunaga T, Sugamura K, Kojima S, Sakamoto T, et al. Elevated plasma osteopontin levels were associated with osteopontin expression of CD4+ T cells in patients with unstable angina. Circ J. 2006;70:851-6.

25. Sanchez PL, Mazzone A. C-reactive protein in degenerative aortic valve stenosis. Cardiovasc Ultrasound. 2006;4:24.

26. Mills WR, Einstadter D, Finkelhor RS. Relation of calcium-phosphorus product to the severity of aortic stenosis in patients with normal renal function. Am J Cardiol. 2004;94:1196-8

27. Weber M, Arnold R, Rau M, Brandt R, Berkovitsch A, Mitrovic V, et al. Relation of N-terminal pro-B-type natriuretic peptide to severity of valvular aortic stenosis. Am J Cardiol. 2004;94:740-5

28. Wada T, McKee MD, Steitz S, Giachelli CM. Calcification of vascular smooth muscle cell cultures: inhibition by osteopontin. Circ Res. 1999;84:166-78. 